\title{
Reflexões sobre a poesia Slam: A coisa tá pReta, de Felipe MARINHO
}

\author{
Aline CAMARa ZAMPIERI* \\ Mariely Zambianco Soares SOUSA ${ }^{* *}$
}

\section{RESUMO}

Este artigo traz algumas reflexões sobre o movimento Slam de poesia na cidade de São Paulo a partir da análise do poema $A$ coisa tá preta (2018), do slammer Felipe Marinho. Por meio da releitura dos fatos e sua ressignificação a partir de demandas presentes na narrativa poética de Marinho, percebemos um discurso que se traduz em objeto histórico, sobressaltando a temática étnico-racial, o racismo, a negritude e o empoderamento negro.

Palavras-Chave: Felipe Marinho; poesia slam; discurso poético.

No texto intitulado Um microfone na mão e uma ideia na cabeça: o poetry slam entra em cena, Roberta Estrela D'Alva, idealizadora e pioneira do movimento no país, define o Slam como uma arte a partir da Slam Poetry. Termo traduzido como batida de poesia, é um estilo poético e performático criado em 1984 por Marc Smith no subúrbio de Chicago, Estados Unidos, que integrava campeonatos em que os poetas participantes, autodenominados marginais, sob a alcunha de slammers,

Professora da Rede Municipal de Ensino de Campo Grande/MS (Reme). Doutora em Estudos Literários pelo Programa de Pós-Graduação em Letras da Universidade Federal de Mato Grosso do Sul/UFMS, Três Lagoas, Mato Grosso do Sul, Brasil. Mestranda no Programa de Pós-Graduação em Letras na Universidade Federal da Paraíba/ UFPB, João Pessoa, Paraíba, Brasil.

E-mail: profalinezampieri@gmail.com ORCID iD https://orcid.org/0000-0003-2473-2006

** Professora da Rede Municipal de Ensino (Reme) de Campo Grande/MS e da Rede Estadual de Ensino (SED/MS). Mestranda pelo Programa de Pós-Graduação em História da Universidade Federal da Grande Dourados/UFGD, Dourados, Mato Grosso do Sul, Brasil. E-mail: mariely.zss@hotmail.com ORCID iD https://orcid.org/0000-0002-3276-0886 
apresentavam suas poesias em performances com o microfone na mão e eram julgados pelo próprio público.

Para o professor, poeta e slammer Daniel Carvalho de Almeida,

O Slam é um evento que ocorre em diversos países e vem crescendo de modo bastante significativo no Brasil. Trata-se de uma 'batalha' de poesias que tratam, geralmente, de questões sociais e apresentam um estilo que remete ao rap. A performance do poeta, o ritmo e cadências que ele imprime ao seu texto, bem como o fato de 'agitar' o público, são critérios importantes, o que justifica o nome desse sarau, uma vez que a palavra slam se refere a um 'grande barulho'. Para participar da batalha, os poetas precisam apresentar texto de autoria própria e que tenham, no máximo, três minutos. Não são permitidos adereços, figurinos ou acompanhamento musical. Os poetas que participam são avaliados por cinco jurados escolhidos no local (ALMEIDA, p. 68, 2017).

A denominação desse sarau de "grande barulho" quanto à reação gerada no público refere-se às performances (ZUMTHOR, 2007) poéticas e ao seu impacto sensorial, à percepção dos sons e movimentos dos poetas pelos expectadores e às suas reações com aclamações e palmas, bem como às suas participações compondo o canto dos hinos de alguns slams e gritos coletivos. O envolvimento do público nas competições é um dos grandes aspectos diferenciadores do movimento. Por essa razão, esse espaço é transicional, na medida em que conecta o autor ao espectador através da percepção e alteridade.

Em contrapartida, a escrita pode ser reconhecida como uma forma discriminatória de comunicação, já que as classes mais destituídas de poder e riquezas majoritariamente não tem acesso à educação. Desse modo, a criação de competições de poesia falada é carregada de intencionalidade:

O slam poetry surgiu para resgatar a poesia, em seu entendimento, uma arte morta. Os autores entendem que declamar uma poesia em público era visto como algo ridículo, de modo que o objetivo do slam era elevar novamente o poeta ao patamar de outros artistas performáticos, como músicos e atores. No universo literário e acadêmico tra- 
dicional, que Smith e Kraynak classificam como elitista, a ênfase no texto praticamente proíbe uma intepretação por parte de quem o declama, o que segundo eles gera desinteresse do público em geral por leituras de poesia (SILVA, 2018, p. 3).

Originado no mesmo contexto do hip hop, ao qual se aproxima quanto à linguagem, às temáticas, aos costumes e valores, o Slam é também de origem popular. D’Alva (2011), faz um balanço desde sua gênese até os dias atuais, destacando-o como um dos mais inventivos movimentos e uma prática democrática de poesia performática:

Foi no ano de 1986, no Green Mill Jazz Club, um bar situado na vizinhança de classe trabalhadora branca no norte de Chicago, nos Estados Unidos, que o operário da construção civil e poeta Mark Kelly Smith, juntamente com o grupo Chicago Poetry Ensemble, criou um "show-cabaré-poético-vaudevilliano" (Smith, Kraynak, 2009: 10) chamado Uptown Poetry Slam, considerado o primeiro poetry slam. Smith, em colaboração com outros artistas, organizava noites de performances poéticas, numa tentativa de popularização da poesia falada em contraponto aos fechados e assépticos círculos acadêmicos. Foi nesse ambiente que o termo poetry slam foi cunhado, emprestando a terminologia "slam" dos torneios de beisebol e bridge, primeiramente para denominar as performances poéticas, e mais tarde as competições de poesia (D’ALVA, 2011, p.120).

Enquanto um movimento de construção de um novo imaginário, calcado em relações ampliadas e estruturadas no espaço urbano, é definido por práticas democráticas devido às estruturas de sociabilidade dos coletivos de slam, constituídas em torno de afinidades ideológicas e culturais, que possibilitam uma integração entre os grupos - daí a consideração de pertencerem a uma comunidade de poetas -, ao mesmo tempo que incentiva a diversidade e variedade:

Sob o ponto de vista prático, as comunidades de slam organizam-se de acordo com suas realidades, e são incentivadas, pelo próprio Marc Smith, a levarem em consideração suas especificidades e a criarem di- 
nâmicas de funcionamento que atendam às suas demandas, para que a prática do slam se torne orgânica e não algo rígido e aprisionador (D’ALVA, 2011, p.121).

Nesse sentido, a celebração da comunidade não ocorre pela uniformização dos grupos e poetas, mas pelo reconhecimento da diversidade de fundamentos e filosofias, mediante um interesse comum: possibilitar momentos de encontro e diálogo, além da tentativa de popularizar a poesia falada.

O movimento expandiu de tal forma que surgiram as competições nacionais nos Estados Unidos e se espalhou em batalhas poéticas pelo mundo, sendo preciso reconhecer particularidades quanto aos coletivos de um país em relação a outro. E mesmo dentro de uma mesma fronteira nacional existem diferenças entre os grupos criados com bases e ideologias próprias e a partir de determinado contexto político, econômico e social.

No caso brasileiro, D’Alva (2011), após uma de suas viagens aos Estados Unidos, traz as batalhas para o coletivo ZAP! - Zona Autônoma da Palavra ${ }^{1}$, situado no bairro da Pompeia, em São Paulo. Posteriormente surgem outros grupos que promovem batalhas com temáticas voltadas para questões étnico-raciais, político-ideológicas e sociais, e de gênero, tornando o Slam um movimento de resistência e espaço de articulação e engajamento político que busca atender às demandas sociais. Ao utilizarem temas sociais como plataforma de suas poesias afirmam-se como sujeitos que pensam e agem sobre a sociedade.

Além disso, essa modalidade é associada à poesia marginal marcada pelo protesto. Segundo Campos (2015), a Literatura Marginal é produzida a partir de 1990 por uma minoria que está à margem dos grandes centros geográficos das cidades, do consumo de bens econômicos e culturais e da participação político-social. Tendo, ademais, afinidades políticas com a

Espaço dedicado à poesia falada. Disponível em: <http://zapslam.blogspot.com.br/search/ label/ZAP>. Acesso em: 18 jun. 2020. 
poesia marginal anterior à década de 1970, reflexo da violência, censura e repressão militar nos anos de ditadura. Para o autor,

[...] a poesia marginal contemporânea se configura como opositora à censura política realizada pelo governo no descaso aos problemas periféricos. A nova marginalidade se manifesta na voz libertária contra a violência, contra a homogeneidade globalizadora e contra o racismo cultural da exclusão (CAMPOS, 2015, p. 126).

Essa consideração é compartilhada por outros autores que levantam ainda outros aspectos da categoria marginal, como sua associação com a transgressão. Segundo Coelho (2013, p. 18),

Hoje, ampliando nosso olhar em torno do tema, podemos compreender com mais acurácia o que se convencionou chamar de 'poesia marginal brasileira' $O$ poeta marginal não pode ser mais definido apenas pelos livros mimeografados que fez (definição a partir do produto), nem apenas pela estreita relação entre poesia, vida e contracultura definição a partir das biografias), nem apenas pela informalidade de uma poética oriunda das perplexidades cotidianas do jovem brasileiro durante a ditadura militar (definição a partir do tema). O poeta marginal era, naquele período, uma reunião contraditória de todos esses aspectos. Ele fazia parte de um compromisso estético coletivo cerzido ao acaso. Participou de um pacto silencioso entre anônimos, descentralizado em suas intenções, mas contundente em seus atos.

Nesse sentido, a poesia baseada na transgressão como ponto de partida, tornou-se marginal, sendo uma categoria ampla cujos poetas e poesias têm características diversificadas. A margem compôs uma identidade e possibilitou um espaço discursivo legítimo de ação, mas acima de tudo, ligada à negação dos cânones culturais, poéticos e estéticos. São esses aspectos que aproximaram a poesia slam brasileira à poesia marginal setentista.

Ainda assim, estabeleceram-se rupturas acompanhadas das influências recebidas da Literatura Periférica, termo cunhado pelo 
escritor Reginaldo Ferreira da Silva (conhecido como Ferréz), que se estabeleceu como crítico ao cânone literário, mas em certa medida também à Poesia Marginal Setentista, cujos ganhos não ofereceram avanços suficientes para os sujeitos das periferias. A Poesia Marginal Setentista rompeu com o cânone, trouxe novas possibilidades estéticas e editoriais, e discursivamente abriu espaço para a participação de pessoas com concepções diversas sobre a realidade. No entanto, na prática, não incorporou os sujeitos marginalizados das periferias e de classes menos favorecidas economicamente e intelectualmente no que tange ao nível de escolaridade e formação.

Ao se apropriar da oralidade, a poesia marginal/periférica proposta pelo movimento slam emerge como forma de combate, já que por meio da palavra organiza as vozes da periferia a questionarem o poder hegemônico, "contribuindo para novas formas de se narrar a cidade" (MIRANDA, 2015, p.13). Nesse sentido, cabe-nos indagar não apenas de que forma o suporte vocal viabiliza a comunicação poética, mas também suas finalidades, reintegrando os aspectos exteriores espaciais relacionados com a escrita e refletindo sobre as questões sociais

Segundo Foucault (2005), são as práticas discursivas que articulam o poder, e que, juntamente com a prática social, formam o pensamento. Nesse sentido, o saber e o conhecimento construídos acerca da realidade se configuram a partir de como se estabelece as relações entre o sujeito e o objeto e de como essas relações são pensadas e descritas. Assim, para entender os saberes produzidos pelos slammers, devemos nos debruçar sobre suas práticas discursivas.

Os participantes, em sua maioria jovens, moradores dos grandes centros urbanos, utilizam a poesia e as performances como plataforma de manifestação de suas angústias, experiências, desigualdades e violências sofridas enquanto sujeitos marginalizados pelo corredor editorial, por habitarem as periferias, pelo uso da linguagem recheada de gírias e palavrões, e ao tematizarem sujeitos e espaços "marginais", abordam valores e práticas peculiares. 
Compreender o movimento Slam e suas manifestações que alcançaram grande público parte da própria demanda de nosso tempo. Demanda de sujeitos que constroem suas próprias narrativas dos fatos e sua(s) identidade(s) a partir do seu lugar de pertencimento. Por isso, cabenos considerar aspectos como os questionamentos que os poetas fazem do que o sociólogo Jessé Souza denomina "paradigmas" do conhecimento:

Um paradigma é o horizonte histórico que define os pressupostos para qualquer tipo de conhecimento. Normalmente, todas as pessoas são influenciadas pelo paradigma na qual são inseridas e ninguém, em condições normais, pensa além de seu tempo (SOUZA, 2019, p.15).

$\mathrm{O}$ autor referiu-se, então, aos paradigmas que marcam as desigualdades em nosso país: o patrimonialismo, nossa suposta herança de corrupção trazida pelos portugueses que compõe o Estado e a elite; e do brasileiro cordial, ambíguo e sentimental, cuja aparente docilidade é fruto da dominação e uma forma de legitimação das desigualdades. Tais ideias sobrepõem a base para a história passada e atual do país: a escravidão. Para tanto, busca destrinchar as estruturas que movem as engrenagens do poder na sociedade brasileira.

Nesse sentido, vemos a obra do poeta Felipe Marinho como reflexões sobre os pressupostos que fundamentam esses paradigmas, pois reconhecemos em seus escritos críticas e problematizações das consequências de mais de três séculos de escravidão: quanto à integração dos negros na sociedade e à questão da pobreza e mazelas sociais decorrentes desse processo histórico.

Para demonstrar tais relações, analisaremos o poema $A$ coisa tá preta (2019, p. 8), de Felipe Marinho.

\section{A COISA TÁ PRETA}

hoje vocês batem panela

ontem o açoite bateu no meu rosto

foram $400 \mathrm{~kg}$ de cocaína 
no helicóptero do perrela

mas a PM só mata

o preto recrutado no morto

já não aceito mais

chibatada nas costas

muito menos tapa na cara

eu entendo o porque das cotas

mas você não entende

seu lugar de fala

mas fomos silenciados

por anos de mordaças

enquanto o discurso

de quem nunca sofreu na pele

sempre foi lindo

mas nunca vi ninguém achar bonito

as nossas balas alojadas

o peso das falhas da lei áurea

todos os minutos que compõe

500 anos

e a pm também assina embaixo

que só existiria racismo reverso

quando você for morto

por ser branco

que eu sou morto por ser "feio"

pelo meu cabelo não ser liso

pela suposta cara de "bandido"

eu, o neguinho

que você sente medo

quando me vê

do outro lado da rua

aquele neguinho 
que passou a vida inteira em branco

que só não foi esquecido

pelo cassetete e a viatura

aquele neguinho

que cês estupraram no canavial

que no tronco cês tiraram o sangue

que hoje cês diminui

mais enfatiza seu pau grande

vocês

que trouxeram doenças

pra nossa América

que matou antigas civilizações

que trouxeram consigo

a antiga bancada evangélica

entendam

preto também tem história

o egito não é branco

rafael braga não é culpado

tira pobre e preto de sujo

mas vocês que lava? jato.

vocês que desfilam e dançam

o nosso samba

o nosso funk

o nosso jazz

de muito dos nossos costumes

e cultura ter parte do candomblé

enquanto vocês já mataram

dizendo: amém

muitos dos nossos já foram salvos

dizendo: axé!

por que por mais que a pele 
seja escura

o coração é maracatu

pois teu clero

depositou mais minha gente

em um tronco

do que sua própria fé numa cruz

não é novidade

que mais um preto foi açoitado

no poste foi amarrado

esse não tinha olhos azuis

mas disseram que bandido bom é bandido

morto

mas não viram

que esse bandido era jesus

ninguém perdoou nossa carne

eu vi vários jesus cristo

apanhando no corpo

de zumbi dos palmares

me disseram

que odeiam cultos africanos

por causa da galinha morta

que na janta come bife

que usa jaqueta de coro

e que é de frango a sua torta

seja na senzala

ou lavando banheiro

no tronco ou quando

na carteira de trabalho

ele te registra

não importa qual a forma 
que o sistema te domina

pretos vocês são lindos

seja com cabelo crespo

ou quando o cabelo você alisa

não se enganem

empoderar-se

é amar seus próprios traços

na semelhança do próximo

mas que fique avisado

que a coisa tá tão preta

mas tão preta

que mais nada vai passar em branco

Felipe Marinho é poeta, slammer e cineasta. Autor do zine Calypso (2017, poemas curtos), foi finalista do campeonato nacional, Slam BR, em 2016 e campeão da grande batalha de poesia falada de SP, o SLAM SP. Como já dito, sua temática comumente abordada em suas produções recai sobre a questão do racismo e da valorização do negro, além de questões sociais e políticas da atualidade.

O poema acima, sem rimas ou métrica regular, é "o grito" de um eu lírico afrodescendente, indignado com a humilhação e o silenciamento do povo negro na sociedade atual. Escrito no ano de 2018, com 20 estrofes e sem quantidade de versos regulares, abusa da linguagem coloquial e da ironia. Predomina o uso de letras minúsculas, mesmo em nomes próprios como rafael braga (na décima estrofe) ou zumbi dos palmares (na décimasexta estrofe), apenas a sigla PM (Polícia Militar), na primeira estrofe, e o nome da poesia é escrito em caixa alta. Há pouco uso de sinais de pontuação, sendo que vírgulas e pontos finais não aparecem ao longo do poema, ressaltando o tom de grito, de desabafo e de indignação do eu lírico.

Destaca-se que, em vários momentos, o eu poeta dirige-se a um determinado grupo de pessoas com o pronome pessoal vocês, como em 
hoje vocês batem panela (primeiro verso); vocês / que trouxeram doenças / pra nossa América (nona estrofe) e vocês que desfilam e dançam / o nosso samba (décima primeira estrofe). Além disso, vocês trata de um público específico: branco, classe média ou classe média alta, que não vivencia na pele as mazelas provocadas pela pobreza e pela herança da escravidão.

O poema faz alusão a episódios brasileiros atuais, como os panelaços, atos realizados em várias cidades brasileiras, entre 2015-2016, em repúdio a corrupção e a favor da deposição da então presidenta Dilma Rousseff. Segundo Magalhães (2020), os panelaços ou cacerolazos, como são mais conhecidos na América Latina de língua espanhola, são uma forma de protesto que se consolidou como parte da história política de vários países do continente, utilizados tanto por militantes de esquerda quanto de direita. No Brasil, o registro do primeiro panelaço foi em 08 de março de 2015, durante um pronunciamento da presidenta, e se tornou uma forma de protesto constante durante as aparições dela.

Além disso, Felipe Marinho cita acontecimentos e personagens significantes para história do povo negro no Brasil, como a Lei Áurea e o Zumbi dos Palmares. Selecionamos, então, algumas dessas referências para demonstrar como aspectos literários e históricos, seja da história recente ou não, configuram o discurso do slammer.

Entre essas menções, destaca-se, na primeira estrofe, a alusão ao helicóptero com 400 quilos de cocaína apreendida pela Polícia Militar, no Espírito Santo, em novembro de 2013. A aeronave que saiu de São Paulo pertencia a empresa Limeira Agropecuária, em nome dos filhos do então Senador Zezé Perrella. Conforme o portal do G1, de Minas Gerais, em 25 de novembro de 2013, o advogado da família Perrella afirmou que a responsabilidade pelo crime é do piloto da aeronave (HELICÓPTERO..., 2013).

Após a menção ao caso acima, nos terceiros e quartos versos, o eu poeta critica a polícia que [...] só mata / o preto recrutado no morto, problematizando as incoerências nas ações da PM e nos discursos daqueles que não sofrem a desigualdade racial. Os mesmos que, conforme a segunda, terceira, quarta e quinta estrofe, questionam as cotas raciais e 
falam sobre o racismo reverso, ignorando o passado de agressões durante a escravidão. Bem como os abusos, a violência e o preconceito contra os negros e sua cultura que se perpetuam após a Lei Áurea, a exemplo do uso das expressões fruto de estigmas ligados ao fenótipo afrodescendente (feio, cara de bandido).

Acrescenta-se ainda, em relação às incoerências da polícia e do sistema criminal, a décima estrofe do poema, na qual o eu lírico menciona Rafael Braga, considerado símbolo da seletividade penal. De acordo com Pina (2018), o catador de material reciclável foi preso pela primeira vez em junho de 2013, durante um protesto pela redução do preço da tarifa do transporte público, da qual não participava, por portar uma garrafa de desinfetante e outra de água sanitária, classificadas como material explosivo.

Em 2016, após passar para o regime aberto, Rafael Braga foi preso novamente por portar 9 gramas de cocaína e pouco mais de meio grama de maconha, segundo o réu, implantados pelos policiais. As condenações desencadearam uma série de discussões sobre o racismo, os direitos humanos e as incoerências penais. Segundo reportagem de Moraes (2017), Lucas da Silveira Sada, um dos advogados que compõe a defesa do réu, classificou os casos como aberração jurídica e denunciou racismo no processo penal:

Rafael é homem, é jovem, é negro, é semianalfabeto e pobre. É a imagem socialmente construída do delinquente que associa o crime e o criminoso a características raciais, estéticas, físicas e econômicas. É com esse estereótipo criminal em mente que as polícias ostensivas do País todo saem às ruas à caça de criminosos. Como funciona o raciocínio policial? Eles viram o Rafael, negro, naquela localidade da vila Cruzeiro, uma localidade que tem tráfico, com uma tornozeleira eletrônica, o estereótipo perfeito do criminoso.

Nos versos dessa estrofe rafael braga não é culpado / tira pobre e preto de sujo / mas vocês que lava? jato, o eu lírico defende o ex-catador de material reciclado, enfatizando as incoerências da polícia e da justiça. 
Aponta, ademais, a hipocrisia dos que tecem acusações aos negros, mas que são corruptos, fazendo referência à Operação Lava Jato ${ }^{2}$ e aos escândalos de corrupção em que muitos políticos e empresários (em sua maioria pessoas brancas e de classe alta) estiveram envolvidos e cujas penas foram atenuadas por acordos de delação premiada e, na maior parte, substituídas por prisões domiciliares. Conforme Modzeleski (2017), a Procuradoria Geral da República informou que até a data de 04 de dezembro de 2017, a Lava Jato contou com 293 acordos de delação premiada homologadas, tais como a de Alberto Youssef, Paulo Roberto Costa, Pedro Barusco, entre outros. line):

Ressalta-se que, segundo o Ministério Público Federal (2020, on-

A operação Lava Jato é a maior investigação de corrupção e lavagem de dinheiro que o Brasil já teve. Estima-se que o volume de recursos desviados dos cofres da Petrobras, maior estatal do país, esteja na casa de bilhões de reais. Soma-se a isso a expressão econômica e política dos suspeitos de participar do esquema de corrupção que envolve a companhia.

Além da denúncia à corrupção no Brasil, Felipe Marinho, em sua narrativa poética, expõe o preconceito à cultura africana no país. Nos versos entre a décima primeira e décima sétima estrofe o eu lírico dirige sua fala para aqueles que se apropriam de sua cultura, como o funk, o samba e o jazz, dentre outros costumes que têm parte do candomblé.

Destaca-se aqui que, de acordo com o dicionário on-line Michaelis ${ }^{3}$, candomblé trata-se de uma religião africana introduzida no Brasil nos primórdios do século XIX pelos povos desse continente, entre eles os nagôs e os bantos que chegaram no Brasil através do tráfico de escravos, e que em suas cerimônias públicas ou secretas demonstra uma forte ligação com os ancestrais e as forças da natureza.

2

3 Disponível em: <https://michaelis.uol.com.br/moderno-portugues/busca/portugues-brasileiro/candombl\%C3\%A9/>. Acesso em: 25 jun. 2020. 
Ao longo de sua história no Brasil, essa vertente religiosa foi bastante modificada em decorrência do contato com outras culturas religiosas, como a indígena e a branca, contribuindo para a criação do sincretismo religioso brasileiro. E, mesmo sendo tombada como patrimônio nacional pelo Instituto do Patrimônio Histórico e Nacional (IPHAN) há 27 anos, essa religiosidade de matriz africana ainda é alvo de intolerância no país, de acordo Puff (2016).

Nos versos citados acima, o eu lírico, além de mostrar em tom irônico um discurso hipócrita e contraditório daqueles que se apropriam da cultura africana e de seus descendentes, reflete sobre as contradições entre a história do cristianismo e a história de sofrimento dos negros durante o período da escravidão: pois teu clero / depositou mais minha gente / em um tronco / do que sua própria fé numa cruz (décima terceira estrofe).

As estrofes resgatam a tradição cristã ao fazer referências ao episódio bíblico da Via Crucis ${ }^{4}$ e a figura de Jesus. Porém, os versos são construídos numa relação antitética no que tange à questão religiosa, pois, para o eu da poesia, o preto amarrado e açoitado no poste não tinha olhos azuis, como a imagem idealizada de Cristo.

Os versos de Rafael Braga comparam o sofrimento dos negros com os martírios provocados pela escravidão, assim como o sofrimento do personagem bíblico, dias antes de sua morte, conforme na décima sexta estrofe: eu vi vários jesus cristo / apanhando no corpo / de zumbi dos palmares.

Mas o eu lírico, nessa mesma estrofe, indaga: ninguém perdoou nossa carne. Aludindo ao preceito cristão de que o Cordeiro de Deus veio para salvar e perdoar a humanidade, enquanto Zumbi de Palmares ${ }^{5}$, como metáfora do povo negro na poesia, continua a ser perseguido.

4 Série de acontecimentos anteriores à Paixão (morte de Cristo) em que se dá a perseguição, o açoitamento, a longa caminhada com a cruz e a crucificação de Jesus Cristo.

5 Zumbi dos Palmares nasceu livre em 1655, no estado de Alagoas. Foi capturado e escravizado, mas ao voltar para o Quilombo de Palmares, comunidade livre formada por escravos fugitivos das fazendas no Brasil Colonial, torna-se líder e ícone da resistência negra à escravidão. 
Ressaltamos que um dos paradigmas questionado pelo poeta é o do rompimento com o passado de escravidão. De forma crítica, ele estabelece que, apesar do fim da escravidão institucionalizada, há continuidades. Conforme destaca Munanga (2006), a correlação entre a desigualdade racial e a de renda é construída ao longo do processo histórico, político e social do país.

É possível constatar por meio de estatísticas que a desigualdade social associada a identificações de cor e raça se reflete em todos os âmbitos: na escolaridade, índices de desemprego, indicadores socioeconômicos, trabalho infantil etc. Segundo uma notícia da Agência IBGE (GOMES; MARLI, 2018) que divulga dados, a taxa de analfabetismo entre brancos é $4,2 \%$, enquanto pretos ou pardos correspondem a 9,9\% em 2016. No mesmo ano, das 1.835 crianças de idade entre 5 e 7 anos trabalhando, $63,8 \%$ eram pretas ou pardas e 35,8\% eram brancas. Ainda de acordo com a notícia, o rendimento médio de todos os trabalhos de brancos é quase o dobro dos pretos em 2017 (brancos: R \$ 2.814; pardos: R\$ 1.606; pretos: R\$ 1.579). No quarto trimestre de 2018, a taxa de desocupação correspondia a $9,5 \%$ brancos, $14,5 \%$ pardos e $13,6 \%$ pretos.

Concomitantemente, o poeta Felipe Marinho estabeleceu um discurso que reflete a sua própria posição na sociedade, a partir dos saberes constitutivos de sua vivência enquanto sujeito negro e periférico sobre o qual influem esses dados estatísticos.

Modificando sua linha narrativa, na décima nona e na vigésima estrofe do poema, o poeta se dirige ao seu povo, num tom de valorização da sua raça: pretos vocês são lindos / seja com cabelo crespo / ou quando o cabelo você alisa. Dessa vez, o uso do pronome pessoal vocês parece dirigirse as pessoas afrodescendentes oprimidos pelo discurso racista e que necessitam reafirmar seu lugar na sociedade. Afinal, para o eu lírico, num jogo de antíteses, [...] a coisa está tão preta / mas tão preta / que mais nada deve passar em branco.

A expressão "a coisa tá preta” também título da poesia analisada, é utilizada quando uma situação está péssima, contrariamente as palavras 
relacionadas ao campo semântico branco são comumente ligadas a algo positivo, enfatizando o caráter racista da expressão.

Conforme o dicionário on-line Aurélio, o verbete preto $\mathrm{I}^{6}$, além de referir-se a pessoas de pele escura, carrega sinônimos como cheio de dificuldades, difícil, complicado, de teor sombrio. Enquanto o termo branco ${ }^{7}$ é associado a claridade, a pureza e a inocência.

$\mathrm{O}$ eu lírico joga com essas palavras em vários momentos do texto, remetendo à clássica oposição dos termos. Porém, na última estrofe, o eu do poema desconstrói o significado comum relacionado ao branco, ao utilizar a expressão passar em branco no sentido de esconder a verdade.

Conforme observamos, em muitas poesias os slammers selecionam aspectos históricos, inscrevendo eventos memoráveis dos quais fazem releituras a partir de sua visão de mundo. Há casos múltiplos em que seus discursos tem pretensão histórica, integram a disputa de interpretações sobre o passado, atribuindo-lhe sentidos próprios. Assim sendo,

[...] o passado se configura, adquire forma, é desenhado na incessante batalha que os homens travam no presente buscando dar a ele uma consistência, um estabilidade, uma memória, que sirvam de suporte para projetos, estratégias, astúcias, que apontam para a construção sobre verdades possíveis sobre o ser do homem no tempo (ALBUQUERQUER JR., 2007, p. 151).

Assim como Felipe Marinho, muitos dos slammers e escritores marginais/periféricos elaboram narrativas sobre o passado interferindo na produção de memória e esquecimento e nos eventos contemporâneos, operam categorias temporais e atestam para uma escrita da história fora do campo da ciência histórica. Ou seja, há demandas pela história que partem de diversos sujeitos e lugares sociais que sugerem autonomia e emancipação em relação às instituições tradicionais, colocando em questão a própria centralidade do historiador nesse processo.

6 Disponível em: <https://www.dicio.com.br/preto/> Acesso em: 29 jun. 2020.

7 Disponível em: <https://www.dicio.com.br/branco/>. Acesso em: 29 jun. 2020. 


\section{CONSIDERAÇÕES FINAIS}

O Slam dentro da literatura é um gênero ainda pouco debatido, assim, ao nos debruçarmos nessa breve análise da poesia de Felipe Marinho, percebemos que o estudo de sua poética não pode ser realizado baseado em teorias e categorizações tradicionais e nem estudado sob a ótica de uma única área de conhecimento.

Afinal, a poesia slam está em sincronia com o presente e o passado e com os lugares que seus artistas representam. Essa forma de arte engajada, de denúncia à opressão vivida pelas minorias (sejam negros, Lésbicas, Gays, Bissexuais, Travestis, Transexuais e Transgêneros, os moradores de comunidades e periferias) legitima seu discurso ao colocar em diálogo os fatos políticos e sociais recentes com acontecimentos históricos sem deixar de retomar (por que não?) a tradição literária.

Reflections on Slam poetry: A coisa tá Preta, by Felipe Marinho

\section{Abstract}

The purpose of this article is to reflect on the Slam Movement of poetry in the city of São Paulo from the analysis of the poem A coisa tá negra [Things look bleak] (2018), by slammer Felipe Marinho. Through the re-reading of the facts and their resignification from the demands present in Marinho's poetic narrative, we perceive a discourse that translates into a historical object, highlighting the ethnic-racial theme, racism, blackness and black empowerment.

KeYwORDs: Felipe Marinho; Slam poetry; poetic speech.

Reflexiones sobre la poesía Slam: A coisa tá preta, de Felipe Marinho

RESUMEN

Este artículo pretende traer algunas reflexiones sobre el Movimiento Slam de poesía en la ciudad de São Paulo a partir del análisis del poema A coisa tá preta [La cosa es negra] (2018), del slammer Felipe Marinho. A través de la relectura de los hechos 
y su resignificación de las demandas presentes en la narrativa poética de Marinho, percibimos un discurso que se traduce en un objeto histórico, destacando el tema étnico-racial, el racismo, la negritud y el empoderamiento negro.

Palabras ClaVe: Felipe Marinho; Slam poesía; Habla poética.

\section{REFERÊNCIAS}

ALBUQUERQUE JR., Durval Muniz de. Ensaios de teoria da História. Bauru: EDUSC, 2007.

ALMEIDA, Daniel Carvalho de. Poesia de resistência na escola pública: compromisso ético e formação de identidade. 2017. 171 f. Dissertação (Mestrado) - Faculdade de Filosofia, Letras e Ciências Humanas, Universidade de São Paulo, São Paulo, 2017.

BÍBLIA. Português. Bíblia sagrada. Tradução Padre Antônio Pereira de Figueredo. Rio de Janeiro: Encyclopaedia Britannica, 1980. Edição Ecumênica.

CAMPOS, Igor Richielli Braga. Poesia e periferia: vozes marginais nos saraus literários do Coletivoz e na poesia de Sérgio Vaz. Revista do Instituto de Ciências Humanas, v. 10, n. 13, p. 106-128, 2015.

DIAS, Cora. Retratos - Saravá! Candomblé é patrimônio nacional. Revista IPEA, Ano 8. Edição 67, set. 2011. Disponível em: <https://www.ipea.gov.br/ desafios/index.php?option $=$ com_content $\&$ view $=$ article $\&$ id $=2568$ : catid=28\&I temid=23>. Acesso em 22 ago. 2020.

D’ALVA, Roberta Estrela. Um microfone na mão e uma ideia na cabeça: o poetry slam entra em cena. Synergies Brésil, n. 9, p. 119-126, 2011.

COELHO, Frederico. Quantas margens cabem em um poema? Poesia marginal ontem, hoje e além. In: FERRAZ, Eucanaã (Org.). Poesia marginal: palavra e livro. São Paulo: Instituto Moreira Salles, 2013. p. 11-41.

FOUCAULT, Michel. O sujeito e o poder. In: DREYFUS, Hubert; HABINOW, Paul. Uma trajetória filosófica: para além do estruturalismo e da hermenêutica. Rio de Janeiro: Forense Universitária, 2005. p. 231-249. 
FUNDAÇÃO CULTURAL PALMARES. Disponível em: <http://www. palmares.gov.br/?page_id=8192>. Acesso em: 27 jun. 2020

GOMES, Irene; MARLI, Mônica. IBGE mostra as cores da desigualdade. Disponível em: <https://agenciadenoticias.ibge.gov.br/agencia-noticias/2012agencia-de-noticias/noticias/21206-ibge-mostra-as-cores-da-desigualdade $>$. Acesso em: 30 jul. 2019.

HELICÓPTERO com cocaína no ES é da família do senador Zezé Perrella. 2013. Disponível em: <http://g1.globo.com/minas-gerais/noticia/2013/11/ helicoptero-com-cocaina-no-es-e-da-familia-do-senador-zeze-perrella.html>. Acesso em: 28 jun. 2020.

MAGALHÃES, Guilherme. Símbolo latino-americano, panelaço marcou Dilma e foi usado de esquerda à direita. 2020. Disponível em: <https://www1.folha.uol. com.br/poder/2020/03/simbolo-latino-americano-panelaco-marcou-dilma-efoi-usado-de-esquerda-a-direita.shtml>. Acesso em: 21 jun. 2020.

MARINHO, Felipe. A coisa tá preta. In: ALCALDE, Emerson; ASSUNÇÃO, Cristina; CHAPÉU, Uilian. (Org.). Slam da Guilhermina: seis ponto zero. São Paulo: YAN comunicação, 2019. p. 8-9.

MINISTÉRIO PÚBLICO FEDERAL. Operação Lava Jato. 2020. Disponível em: <http://www.mpf.mp.br/grandes-casos/lava-jato>. Acesso em: 28 jun. 2020.

MIRANDA, Cláudia de Azevedo. Slams e saraus: espaços táticos da periferia na cultura urbana. In: CONGRESSO BRASILEIRO DE CIÊNCIAS DA COMUNICAÇÃO, 38., 2015, Rio de Janeiro. Anais... Rio de Janeiro: Intercom, 2015.

MODZELESKI, Alessandra. Lava Jato tem 293 acordos de delação premiada homologados, diz PGR. 2017. Disponível em: <https://g1.globo.com/politica/ noticia/lava-jato-teve-293-acordos-de-delacao-homologados-diz-pgr.ghtml> Acesso em: 28 jun. 2020.

MORAES, Geórgia. Comissão de Direitos Humanos denuncia racismo contra jovem negro preso no Rio de Janeiro. 2017. Disponível em: <https://www.camara.leg. $\mathrm{br} /$ noticias/521825-comissao-de-direitos-humanos-denuncia-racismo-contrajovem-negro-preso-no-rio-de-janeiro/>. Acesso em: 25 jun. 2020.

MUNANGA, Kabengele. O negro no Brasil de hoje. São Paulo: Global, 2006. 
PINA, Rute. Símbolo da seletividade penal, caso Rafael Braga completa cinco anos. 2018. Disponível em: <https://www.brasildefato.com.br/2018/06/20/ simbolo-da-seletividade-penal-caso-rafael-braga-completa-cinco-anos/>. Acesso em: 21 jun. 2020.

PUFF, Jeferson. Por que as religiões de matriz africana são o principal alvo de intolerância no Brasil? BBC Brasil, Rio de Janeiro, 21 jan. 2016. Disponível em: <https://www.bbc.com/portuguese/noticias/2016/01/160120_intolerancia_ religioes_africanas_jp_rm>.Acesso em: 22 ago. 2020.

SILVA, Caio Ruano da. Posicionando o Slam Poetry no debate da teoria política. In: SEMINÁRIO DE CIÊNCIAS SOCIAIS, 3., 2018, Espírito Santo. Anais... Vitória: UFES, 2018.

SOUZA, Jessé. A elite do atraso. Rio de Janeiro: Estação Brasil, 2019.

VEYNE, Paul. Uma história sociológica das verdades: saber, poder, dispositivo. In: MORAES, Marcelo Jacques de; VEYNE, Paul (Org.). Foucault, seu pensamento, sua pessoa. Rio de Janeiro: Civilização Brasileira, 2011. p.163-192.

ZUMTHOR, Paul. Performance, recepção e leitura. Tradução Jerusa Pires Ferreira, Suely Fenerich. 2. ed. São Paulo: Cosac Naify, 2007.

Submetido em 30 de junho de 2020

Aceito em 23 de agosto de 2020

Publicado em 30 de setembro de 2020 